Using Interpersonal Process Recall in clinical supervision to enhance supervisees' multicultural awareness

By: Nathaniel N. Ivers, Jennifer L. Rogers, L. DiAnne Borders, and Alison Turner

Ivers, N. N., Rogers, J. L., Borders, L. D., \& Turner, A. (2017). Using Interpersonal Process Recall in clinical supervision to enhance supervisees' multicultural awareness. The Clinical Supervisor, 36, 282-303. https://doi.org/10.1080/07325223.2017.1320253

This is an Accepted Manuscript of an article published by Taylor \& Francis in The Clinical Supervisor on 09 May 2017, available online: http://www.tandfonline.com/10.1080/07325223.2017.1320253

***@ 2017 Taylor \& Francis. Reprinted with permission. No further reproduction is authorized without written permission from Taylor \& Francis. This version of the document is not the version of record. Figures and/or pictures may be missing from this format of the document. ***

\begin{abstract}
:
We describe the use of interpersonal process recall (IPR) in supervision to help supervisees increase their multicultural awareness. Specifically, we examine the relationship between the use of IPR and the development of multicultural awareness, share a list of IPR inquiries, and provide a case example illustrating the use of IPR in supervision to facilitate multicultural awareness. We also discuss implications for supervision, supervision training, and future research.
\end{abstract}

Keywords: Multicultural awareness | interpersonal process recall | supervision interventions

\title{
Article:
}

Research on the effectiveness of multicultural training indicates that traditional multicultural training practices (e.g., content-based multicultural courses) are effective in facilitating development of some components of multicultural competence, such as multicultural knowledge, but may fall short of increasing students' multicultural awareness (Dickson \& Jepsen, 2007). In this article, we present a conceptual argument for using an adapted form of interpersonal process recall (IPR; Kagan, Krathwohl, \& Miller, 1963) in clinical supervision to facilitate supervisees' development of multicultural awareness. In doing so, we define multicultural awareness and IPR and review pertinent literature pertaining to each concept. We also describe how IPR may be utilized in clinical supervision to help counselors increase their multicultural awareness.

\section{Multicultural awareness}

Multicultural awareness is a clinician's recognition of his or her own cultural heritage, as well as his or her biases and prejudices toward differing cultural worldviews and culturally diverse individuals (Sue, Arredondo, \& McDavis, 1992 S). A culturally aware clinician "is one who is actively in the process of becoming aware of his or her own assumptions about human behavior, 
values, biases, preconceived notions, personal limitations, and so forth" (Sue et al., 1992, p. 481). Culturally aware clinicians recognize they are a product of cultural conditioning and acknowledge that it may manifest in or interfere with their counseling work with culturally diverse clients. As such, an important aspect in developing multicultural awareness is recognition and avoidance of ethnocentrism (Sue et al., 1992). Culturally aware clinicians also recognize the scope of their expertise and limits of their competence, and they are comfortable with cultural differences between themselves and their clients in terms of cultural worldviews, values and beliefs, race, and ethnicity (Sue et al., 1992). The most recent Association for Multicultural Counseling and Development (AMCD) Model of Multicultural Counseling Competence and Social Justice also highlights the importance of counselors being aware of their own power and privilege relative to the power and privilege of their clients (Ratts, Singh, Nassar-McMillan, Butler, \& McCullough, 2015).

Researchers (e.g., Chao, 2012; Dickson \& Jepsen, 2007) have revealed that multicultural training in the traditional sense (e.g., multicultural coursework, multicultural workshops) is inadequate in fostering the development of multicultural awareness. Chao (2012), for example, operationalized multicultural training in terms of the number of multicultural courses, research projects, and workshops participants had completed in graduate school. Results of Chao's (2012) study showed positive interaction effects on multicultural knowledge for the combination of multicultural training and racial/ethnic identity development. Results also indicated positive interaction effects on multicultural knowledge for multicultural training and gender-role attitudes. However, results revealed no significant interaction effects for multicultural awareness. Dickson and Jepsen (2007), using a correlational research design, assessed the impact of various training program variables on counseling students' multicultural counseling competence (MCC). These variables encompassed multicultural instructional strategies, including traditional (e.g., lecture), exposure (e.g., immersion experiences), and participatory (e.g., classroom simulations, role plays) strategies, as well as students' perceptions of their counseling program's emphasis on multicultural issues (e.g., honesty in recruitment, comfort) and multicultural clinical experiences (i.e., multicultural practica, multicultural supervision). Among other things, results indicated that traditional instructional strategies were not related to students' self-perceived multicultural competence, including multicultural awareness. Conversely, students' perceptions of the emphasis placed on multicultural issues in their programs and their multicultural practicum experiences were positively correlated with multicultural awareness.

With respect to practicum, supervision in clinical courses is a critical place to emphasize the development of multicultural awareness (Dickson \& Jepsen, 2007; Toporek, Ortega-Villalobos, $\&$ Pope-Davis, 2004). Toporek and colleagues (2004) shared that "one of the most reasonable goals" in supervision is to increase supervisees' multicultural awareness (p. 80). Leong and Wagner (1994) suggested that supervisees' cultural awareness progresses in stages during supervision, from limited cultural awareness to recognition of cultural differences between themselves and their clients, and then to a more integrated multicultural identity. Supervisors can facilitate cultural awareness by processing supervisees' cultural beliefs and attitudes, encouraging them to express their emotions regarding cultural issues, and validating their internal conflicts and cognitive dissonance (Fong, 1994). 
A core factor associated with developing supervisees' cultural awareness in supervision is a strong supervisory working alliance (Bennett, Mohr, Deal, \& Hwang, 2012; Cary \& Marques, 2007; Crockett \& Hays, 2015). This alliance is strengthened when supervisors themselves are multiculturally competent and address multicultural issues frequently in supervision (Crockett \& Hays, 2015). It also is enhanced when supervisors acknowledge differences between their own cultural values and beliefs compared to those of their supervisees (Cary \& Marques, 2007; Crockett \& Hays, 2015).

Along with expressing the importance of a strong supervisory working alliance, multicultural theorists and supervisors have proposed specific strategies, frameworks, and techniques for fostering supervisees' MCC development. Constantine (1997) proposed a direct supervisory approach in which supervisors use semi-structured questions to help themselves and their supervisees increase awareness of their cultural identities and acknowledge how their cultural identities affect their counseling and supervisory relationships. Inman and DeBoer Kreider (2013) suggested two supervision models for facilitating supervisees' MCC development, the Critical Events Model and the Heuristic Model of Nonoppressive Interpersonal Development (Ladany, Friedlander, \& Nelson, 2005). In the Critical Events Model, supervisors emphasize critical events (markers) that occur in supervisees' cross-cultural counseling sessions, such as when supervisees minimize the influence of culture on the counselor-client relationship or in relation to clients' presenting concerns. In the Heuristic Model of Nonoppressive Interpersonal Development, supervisors focus on their own multicultural identity development as well as that of their supervisees when determining how and when to address topics in supervision that potentially are culturally sensitive.

Sommer and colleagues (2009) proposed the use of stories, such as myths and classical fairy tales, to foster supervisees' multicultural awareness. The authors noted that supervisors can use stories in supervision to facilitate meaning making, connect universal elements of humanity with personal characteristics, support group discussions, and elicit reactions and reflections of personal and cultural values. In a similar vein, Suthakaran (2011) suggested that supervisors use narratives in the form of analogies to enhance supervisees' self-awareness and cultural empathy. In addition, Lassiter, Napolitano, Culbreth, and $\mathrm{Ng}$ (2008) described an adapted version of the structured peer group supervision model originally proposed by Borders (1991) to include an overt emphasis on multicultural awareness and skills development.

Although potentially helpful, each of these supervisory frameworks and strategies have some limitations, including the absence of empirical support. A potential limitation of Constantine's (1997) intervention is that it is directive. A supervisor using a directive approach, such as that proposed by Constantine (1997), may be more reliant upon supervisees' conscious awareness of culture and the supervisees' willingness to self-disclose. Moreover, this approach may evoke defensive or otherwise resistant reactions among supervisees who are less aware or unaware of their own cultural issues (Cashwell, Looby, \& Housley, 1997). The stories and analogies techniques are less directive but also less personal, and thus are potentially more difficult for supervisees to apply to themselves or to their clinical work. The critical incidents and heuristics models are helpful, nice frameworks under which supervisors may work to help supervisees develop their multicultural awareness. However, these models do not provide specific guidance on interventions supervisors may employ once they have identified critical incidents or assessed 
for multicultural identity development. IPR (Kagan et al., 1963) is an alternative or complement to these supervisory methods, in that it is a technique supervisors can use with supervisees to foster a deep awareness of intra- and interpersonal processes in a more personal, less directive, and potentially less threatening way. Due to its focus on and specific process for increasing intraand interpersonal awareness (Kagan \& Kagan, 1990), IPR seems particularly appropriate to use within the frameworks of the critical incident and heuristic models.

\section{Interpersonal process recall}

IPR (Kagan et al., 1963) refers to a specific technique designed to help people increase their awareness of self and others, with the ultimate goal of helping them become more skilled and effective professionals. A variety of professionals, including counselors, psychiatrists, medical professionals, clergy, teachers, and police officers, have used IPR to facilitate interpersonal communication and awareness (Kagan, 1976). In the context of clinical supervision, a supervisor and supervisee review together a supervisee's recorded counseling session, pausing the recording periodically and intentionally to identify the supervisee's covert thoughts and feelings during the session. In contrast to an instructional role, the supervisor assumes the role of a nonjudgmental "inquirer," asking questions to help supervisees re-experience and express their recalled thoughts and feelings (Kagan, 1976).

There are four main goals of IPR:

1. increase awareness of covert thoughts and feelings;

2. practice expressing those thoughts and feelings in the here-and-now without feared consequences;

3. discover how and where counselors fail to deal with clients' interpersonal messages and their own feelings; and

4. increase involvement with clients via immediacy (Kagan, 1980).

Kagan and colleagues (1963) discovered that, when people record interactions with another person, after the interaction they are able to recall thoughts and feelings associated with their interaction with incredible depth and precision. Results from Kagan and colleagues' (1963) analyses also indicated that inquirers (i.e., supervisors), or those who facilitate the recall of thoughts and feelings associated with another person's recorded interactions, are integral to the process. Specifically, they found that active encouragement by inquirers, as opposed to judgment or confrontation, was more effective in helping individuals recall their thoughts and feelings.

Based on extensive research, Kagan and Kagan (1997) listed eight reasons why IPR is effective as a tool for helping people enhance their intra- and interpersonal awareness. First, IPR allows individuals to confront their interpersonal weaknesses in a non-threatening way. Second, because skill training is not enough to develop improved interpersonal abilities, IPR helps people "develop an awareness and understanding of their underlying thoughts and feelings without being overwhelmed by them" (p. 306). Third, when used in groups, IPR allows people to expand their ability to express inner feelings and thoughts. Fourth, IPR offers people the opportunity to practice new behaviors, specifically the act of expressing unexpressed thoughts and feelings (particularly negative ones) in a safe environment. As they express these thoughts and feelings, 
they can begin to recognize the non-threatening nature of them. Fifth, IPR affords individuals the opportunity to learn assertive behaviors through the recall of feelings and the processing of thoughts that were and were not shared. Sixth, IPR helps people gain a greater understanding of their own and others' here-and-now thoughts and feelings about their relationship. Seventh, IPR helps people learn how to incorporate their awareness of here-and-now interactions into an ability to respond to others in new ways. Eighth, what one learns from an IPR session can be generalized to other relationships and interactions.

Researchers also have examined the effectiveness of IPR specifically in supervision. Kagan and colleagues (1967), using a pre-, post-, and between-treatment design, compared IPR to more traditional supervision. The authors defined traditional supervision as "supervision that did not employ stimulated recall via videotape" (p. 97). Practicum supervisees randomly assigned to both supervision groups demonstrated increases in affective, understanding, specific, exploratory, and effective verbal responses. IPR supervisees, however, scored significantly higher on client ratings of empathic understanding and positive regard, as well as on expert observer ratings of counselors' interview behaviors. Kingdon (1975) found that, after three sessions, clients whose supervisees were randomly assigned to the IPR group disclosed information with greater depth than did clients whose supervisees were assigned to a traditional supervision group. Conversely, Kingdon (1975), who defined traditional supervision similar to Kagan and colleagues (1967), found no differences between IPR and traditional counseling on supervisees' empathic understanding, client satisfaction, supervisor ratings of counselors' performance, and clients' self-reports of inhibition across sessions.

Other researchers (Baker, Daniels, \& Greeley, 1990; Crews et al., 2005) also found no outcome differences between IPR and other supervision techniques. Baker and colleagues (1990) conducted a meta-analytic review of IPR, microcounseling (MC), and human resource training (HRT) in reference to supervisees' skill development. Results indicated a strong effect size for HRT, a moderate effect size for MC, and a small effect size for IPR. Crews and colleagues (2005) compared IPR to the Skilled Counselor Training Model (SCTM) on the Skilled Counselor Scale. Results indicated that students in both groups improved their skills, but those in the SCTM group experienced greater improvement. It is important to note that, in both of these studies, researchers assessed skill development rather than self-awareness. In response to Baker and colleagues (1990), Kagan and Kagan (1990) shared the following: "Logically, one would expect HRT would have the largest gains in specific skills acquisition, that MC would show less skills acquisition and IPR would show the least. Indeed, IPR is not a skill training model" (p. 436). Rather, the emphasis of IPR is the development of interpersonal and intrapersonal awareness (Kagan \& Kagan, 1990), which is highly relevant to multicultural awareness.

\section{Interpersonal process recall and supervision from a multicultural perspective}

IPR, with its focus on intrapersonal and interpersonal awareness, can be a relevant tool for supervisors working to enhance supervisees' multicultural awareness (Cashwell et al., 1997; Garrett et al., 2001). In fact, Cashwell and colleagues (1997) pointed out that IPR, with its personal and process-oriented focus, may challenge, and ultimately defeat, resistance in supervisees who have not previously been made aware of their cultural blind spots. Garrett and colleagues (2001) proposed supervisors utilize IPR to address supervisees' perceptions regarding 
their interactions with clients. Although authors have promoted the use of IPR in supervision for multicultural counseling, to our knowledge, an MCC-specific format of IPR, including culturally focused inquiry questions, has not yet been proposed. Whereas the goal of traditional IPR is to increase supervisees' general self-awareness, the impetus for adapting IPR is to focus specifically on fostering supervisees' development cultural awareness.

From an intrapersonal perspective, supervisors using IPR can help supervisees recognize unconscious cultural values, beliefs, attitudes, and behaviors that could affect their interaction and relationship with culturally diverse clients. Supervisees who are unaware of their own ethnocentricities, biases, and prejudices, or who are unfamiliar with their own cultural values and beliefs, may be less prepared to work effectively with culturally contrastive clients (Ratts et al., 2015; Sue et al., 1992). As a result, these supervisees may feel less connected with their culturally diverse clients, or more defensive or guarded around them.

From an interpersonal perspective, a clinician who fails to take into account the potential influence of culture on a client's life, including the role of culture in the development of the therapeutic relationship, may miss an important conceptual component of the client's story. This, in turn, may negatively affect the counseling process, from rapport building and empathy expression to case conceptualization and treatment delivery. Kagan (1980), in discussing the importance of IPR in developing self-awareness, asserted that unexamined feelings and beliefs can lead counselors to feign clinical naiveté, wherein they become reluctant or unable to engage clients at a certain level. Clinicians who are unwilling or unable to become involved with clients on a cultural level may be committing a form of microaggression called a microinvalidation. Microaggressions are obscure attacks or insults aimed at culturally diverse individuals, which may or may not be intentional, but which still belittle and marginalize (Sue et al., 2007). A microinvalidation occurs when individuals intentionally or unintentionally discredit or fail to acknowledge the cultural realities or experiences of another individual (Sue et al., 2007).

The success of IPR in raising supervisees' self- and multicultural awareness is influenced by supervisors' preparation for IPR. First, it is important that supervisors develop a supervisory working alliance with their supervisees before introducing IPR. This includes creating a safe and secure space wherein supervisees feel respected, valued, and supported (Crockett \& Hays, 2015). An important aspect of creating a strong supervisory working alliance is recognizing and addressing cultural differences between the supervisor and supervisee (Crockett \& Hays, 2015). Second, it is important that supervisors understand their role in IPR. The IPR inquirer role, in contrast and complementary to many other supervision approaches, does not include analysis and evaluation of counselor responses and counselor-client interactions. Parenthetically, this does not mean that supervisors who use IPR in supervision always avoid analysis and evaluation with their supervisees; rather, it means that supervisors make a concerted effort while in the inquirer role of IPR to avoid expressing any thoughts that would reflect analysis or evaluation. It may be helpful for supervisors to practice with and receive feedback from colleagues or supervisors of supervision before employing IPR with supervisees (Borders \& Brown, 2005). Third, because the focus of IPR in this case is self- and multicultural awareness, it is paramount that supervisors be aware of and take steps to develop their own multicultural awareness. Fourth, it is important that supervisors consider how they introduce IPR to supervisees. 
With respect to introducing the IPR exercise, it is essential that supervisors share with supervisees how IPR differs from other reviews of recorded counseling sessions in terms of supervisor and supervisee roles, expectations, and goals. In particular, it is helpful for supervisors to highlight that their role in IPR is not that of analyzer or evaluator. Rather, they are there to help supervisees re-experience counselor-client interactions and gain insight into their interpersonal and self-awareness. Supervisors can prepare supervisees for their role in IPR by giving permission to supervisees to say whatever it is they were thinking and feeling during their counselor-client interactions, and by indicating there is no right or wrong answer. It can be helpful to ask supervisees to think about impressions they had of their client during the session, beliefs about their client's impressions of them, ideas supervisees would have liked to have shared in session, images that came to them, or bodily reactions they had (Borders \& Brown, 2005). Borders and Brown (2005) shared that one way to prepare supervisees for an IPR session is to ask supervisees before starting the review of the recording to try to recall what they were thinking and feeling before meeting with the client. Borders and Brown (2005) also recommended that supervisees use present tense when responding to inquirer questions to facilitate recall (now versus then focus).

In regards to understanding the inquirer role, when utilizing IPR it is important that supervisors "maintain a nonjudgmental stance and be accepting of negative feelings, including any negative thoughts and feelings about the client" (Borders \& Brown, 2005, p. 44). The responsibility of supervisors is to listen and to absorb rather than to teach or to evaluate (Borders \& Brown, 2005). Even subtle evaluative questions (e.g., Did you notice her shift her body position?) fall outside the inquirer role and may negatively affect supervisees' ability or willingness to share openly their impressions and feelings during the session. Evaluative statements also may result in supervisees explaining or defending beliefs and actions during the session (Borders \& Brown, 2005). In cross-cultural counseling relationships, evaluative questions may be particularly detrimental to open exploration of cultural beliefs and attitudes.

A supervisor employs IPR to enhance multicultural awareness by reviewing with the supervisee a recording of the supervisee's counseling session with a culturally diverse client. While reviewing the recording, supervisees stop the recording at key moments to reflect upon their thoughts, feelings, and responses. Supervisors may also stop the recording, particularly when introducing IPR to practicum and internship students or others new to IPR, to help supervisees understand the expectations of the process. However, it is important that supervisors keep in mind that stopping the tape in and of itself can communicate evaluation and judgment.

Supervisors help supervisees to reflect upon their perceptions of their client's thoughts and feelings, as well as their own beliefs about interactions between the supervisee and client. At these stopping points, the supervisor asks questions of the supervisee that focus the recall on selfand cultural awareness.

The questions that supervisors ask during IPR are integral to its effectiveness. Harris and Werner (1976) organized potential IPR inquirer (supervisor) questions into categories, including questions that encourage emotional exploration, cognitive examination, and explorations of body sensations, images, mutual perceptions, associations, and unspoken agendas. Using this framework, we compiled a list of questions that supervisors can use to help supervisees enhance their multicultural awareness (see Table 1 and text). Supervisors can choose questions from a 
specific focus or mix them, as needed, to promote supervisees' cultural awareness. With respect to affect, counseling often brings up strong feelings for clients, but may also bring up strong feelings for counselors, particularly in cross-cultural counseling contexts. Supervisors wanting to explore supervisees' affective responses to specific moments from a session may consider using affective inquiries (e.g., "How were you feeling when your client shared...?"). Cognitivefocused inquiries target what counselors are thinking about in session and links to their conceptualization of a client (e.g., "What thoughts were you having about your client in that moment?"). Culture plays a role in that conceptualization (Ratts et al., 2015; Sue et al., 1992).

Table 1. IPR multicultural questions organized by focus of examination.

\begin{tabular}{|c|c|}
\hline Focus & IPR multicultural questions \\
\hline Affective & $\begin{array}{l}\text { - What were you feeling when your client shared his or her concerns about having a } \\
\text { - heterosexual/White/ethnic minority/female/male counselor? } \\
\text { - How do those feelings mean for you? } \\
\text { - How did those feelings thas you identified affect you while you were in session and/or after } \\
\text { - session? } \\
\text { - If you consider expressing or disclosing your feelings to your client? } \\
\text { - If so, what kept you from sharing those feelings? }\end{array}$ \\
\hline Cognitive & $\begin{array}{l}\text { - What do you recall thinking when your client shared...? (focused on race, culture, injustice, } \\
\text { prejudice, identity development) } \\
\text { - What thoughts were you having about your client when he or she shared...? (something } \\
\text { about culture) } \\
\text { - If you shared your thoughts with the client, were you able to express yourself how you } \\
\text { wanted to? } \\
\text { - At this moment, do you recall any plans for how you wanted the counseling session to } \\
\text { proceed? } \\
\text { What image do you believe you projected in that moment? Is that the image you wanted to } \\
\text { portray? }\end{array}$ \\
\hline $\begin{array}{l}\text { Body } \\
\text { sensations }\end{array}$ & $\begin{array}{l}\text { - In that moment (after client shared something about culture, race, ethnic identity, } \\
\text { discrimination), did you feel anything in your body? If so, how did it feel? } \\
\text { - Where in your body did you most feel it? } \\
\text { - If that feeling in your body were able to speak, what would it share? }\end{array}$ \\
\hline Images & $\begin{array}{l}\text { Do you recall any images, memories, or pictures appearing in your mind at this moment } \\
\text { when your client shared...? } \\
\text { - Did you, by chance, have a nostalgic feeling at this moment, like you had experienced this } \\
\text { before or it was familiar to you? } \\
\text { - If this moment took you back to a different time, what did it remind you of? What thoughts } \\
\text { and emotions did it elicit? }\end{array}$ \\
\hline Expectations & $\begin{array}{l}\text { - What did you want your client to share with you regarding...? (information related to } \\
\text { - culture, race, discrimination) } \\
\text { - Were you expecting anything in particular from your client at that moment? } \\
\text { - } \quad \text { Wid you want your client to perceive you in any particular way at that point? } \\
\text { - What message(s) did you want to share with your client at that moment? } \\
\text { - What did you want your client to think or say of you? } \\
\text { - Did it seem like the two of you were on the same page? }\end{array}$ \\
\hline $\begin{array}{l}\text { Mutual } \\
\text { perceptions }\end{array}$ & $\begin{array}{l}\text { - How do you think your client was viewing you at that moment? } \\
\text { - Do you think your client was aware of your thoughts and feelings at that moment? } \\
\text { - What do you think your client wanted from you in that moment or during the session? } \\
\text { - What message(s) do you think your client was trying to send to you? }\end{array}$ \\
\hline
\end{tabular}




\begin{tabular}{|c|c|}
\hline Focus & IPR multicultural questions \\
\hline & $\begin{array}{l}\text { - What expectations do you think your client had of you at that point or during the session? } \\
\text { - What do you think your client wanted you to think or feel at that moment? } \\
\text { - How do you think your description of the interaction would be similar to or different from } \\
\text { that of your client's? } \\
\text { - How do you believe your client felt about discussing culture/race/discrimination/injustice at } \\
\text { that moment with you? } \\
\text { Based on what you could tell from your client's reaction, do you think he or she will be } \\
\text { comfortable to continue discussing these topics with you? } \\
\text { How do you think your client felt about continuing to discuss that topic with you at that } \\
\text { point? }\end{array}$ \\
\hline Associations & $\begin{array}{l}\text { - Did your client remind you of another person in your life? If so, what effect did that have } \\
\text { on you? } \\
\text { What reaction did you have to your client's (culture/group affiliation/appearance [e.g., skin } \\
\text { color, accent, disability, sexual orientation, religious/spiritual beliefs])? }\end{array}$ \\
\hline \begin{tabular}{|l} 
Unstated \\
agendas
\end{tabular} & $\begin{array}{l}\text { - What would you have liked to say to your client at that moment? } \\
\text { - What were your intentions in giving that response? } \\
\text { - If you had had more time, where would you have liked to have taken the session? } \\
\text { - When you realized that your plan for the session conflicted with your client's plan, what } \\
\text { did you feel/think? }\end{array}$ \\
\hline Ending & $\begin{array}{l}\text { - What did you like/dislike about what you heard/saw in the recording? } \\
\text { - In retrospect, how do you think you felt about the session? About your client? } \\
\text { - What did you learn about yourself as a cultural being during this exercise? } \\
\text { - What would you like to work on based on the insights you gleaned from this exercise? } \\
\text { - If you were able to redo the session or particular moments during the session, what would } \\
\text { - you do differently? } \\
\text { - Are there any portions of the recording that you would like to review again? }\end{array}$ \\
\hline
\end{tabular}

Note. Source: Adapted from Harris \& Werner, 1976, pp. 186-190.

Supervisors may also tap into supervisees' self- and multicultural awareness during crosscultural counseling sessions by inquiring about counselors' body sensations and images. Body sensation inquiries focus on physiological responses or feelings that counselors have during their counseling session that often act as signals for interpersonal comfort and discomfort. An example of a body sensation question related to multicultural concepts is, "In that moment [after client shared something about culture, race, ethnic identity, discrimination], did you feel anything in your body? If so, how did it feel?" (Harris \& Werner, 1976, p. 186). Images often are strongly linked to memories in the past, and can be emotionally bound. An example of an image question is, "Do you recall any images, memories, or pictures appearing in your mind at this moment when your client shared...?" (Harris \& Werner, 1976, p. 187).

Supervisors may also use inquiries that focus on expectations, mutual perceptions, associations, and unstated agendas to facilitate multicultural awareness. Inquiries regarding expectations focus on the hopes supervisees have for their clients, as well as supervisees' perceptions of clients' expectations for themselves and for the counselor. An example of an expectations inquiry is, "What did you want your client to share with you regarding...?" (Harris \& Werner, 1976, p. 187). Mutual perceptions inquiries focus on counselors' perceptions of how they believe they are being perceived by their client and their own perceptions of their client. An example of a mutual perception inquiry is, "What message(s) do you think your client was trying to send to you?" (Harris \& Werner, 1976, p. 187). Association questions are related to the concepts of 
transference and countertransference. These questions focus on supervisees' awareness of their own interpersonal processes while in session, such as whether the client reminded the counselor of someone else and how that affected the counselor. An example of an association question is, "What reaction did you have to your client's [culture/group affiliation/appearance (e.g., skin color, accent, disability, sexual orientation, religious/spiritual beliefs)]?" (Harris \& Werner, 1976, p. 188). Inquiries regarding unstated agendas can be useful in processing supervisees' latent objectives for their clients or the intentionality behind their responses. An example of an unstated agenda inquiry is, "If you had had more time, where would you have liked to have taken the session?" (Harris \& Werner, 1976, p. 188).

Ending questions are useful to wrap up an IPR supervision session. Questions that can guide an IPR wrap-up may include, "In retrospect, how do you think you felt about the session? About your client?" or "What did you learn about yourself as a cultural being during this exercise?" It might also be helpful to ask, "If you were able to redo the session or particular moments during the session, what would you do differently?" or "Are there any portions of the recording that you would like to review again?" (Harris \& Werner, 1976, p. 189).

\section{Case example}

The following hypothetical case example represents an application of IPR as a supervision tool for developing multicultural awareness of supervisees. (IPR inquiries are labeled by category throughout the case example.) In this example, Paula $(\mathrm{P})$ is a self-identified White, able-bodied, lesbian, middle-class, 40-year-old university internship supervisor who grew up in the Midwest region of the United States. Maddie (M) is a self-identified White, able-bodied, heterosexual, 24year-old counseling student intern working in a community mental health clinic that serves primarily low-income clients. Originally from the Northeast region of the United States, Maddie was raised in an upper-class family. Amy (A) is a self-identified Black, able-bodied, heterosexual, 32-year-old child care provider in a large day care center. She has three children, ages 10,8 , and 2. She is in a committed relationship with John, the father of her youngest child, who has several as-needed, part-time positions in the construction industry. Amy is a new client of Maddie's, with whom she has met three times. Amy self-referred to the clinic with symptoms of anxiety and depression.

Maddie, like all students at this institution, had been informed, via program materials and the course syllabus, that self-awareness is an expected part of the supervision process and may involve students examining personal information and issues to the extent that this information and these issues are limiting the students' ability to develop competence or provide effective client care. Paula and Maddie have a well-established supervisory working alliance, and have been working together in individual and group supervision for a full semester. Paula has been to a number of trainings related to multicultural competency development. Accordingly, Paula and Maddie have addressed issues related to culture in previous sessions, including their own culturally contrastive beliefs, values, and identities. In particular, they have discussed worldview differences based on age and class identity. These previous discussions, particularly concerning class, have opened Maddie's mind to the idea that her view of reality is influenced by her cultural identities and may differ from others. Maddie has come to today's supervision session with a specific section of audio recording she would like to review. 
M: I have the recorder cued up to something that happened yesterday in my session with a client. I have no idea what was going on. I felt weird about it afterwards.

P: All right. Maybe we can make some sense of it by slowing things down a bit. What I would like to try today in reviewing your session recording is a technique called interpersonal process recall. So, while we're listening to your recording, when there is something that captures your attention, raises a question, triggers an idea or emotion, or anything along those lines, you can pause the recording and then I will ask you some questions to help you recall the thoughts and feelings you were experiencing at that moment during the session. Okay? The idea is that, during a session, we have a lot more going on in our minds than we can share or process in that moment. The goal of this technique is to recognize some of these thoughts, impressions, and feelings to see what we can glean from them. There are no right or wrong answers to the questions.

M: Okay. That sounds like it might be helpful.

P: To set the stage, could you share with me the thoughts and feelings you were having just before this session began, what your impressions of your client were, and what her reactions to you were as you greeted each other?

M: Although the session just happened yesterday, I'm having a hard time remembering. I guess I was a little nervous because Amy and I are still getting used to each other. I'm still trying to figure out how to connect with her. I remember wondering before the session whether Amy felt counseling was beneficial to her and if she thought I was a good counselor for her. It kind of sounds silly, but I wondered if she liked me. When we greeted each other, she seemed tense.

P: Okay. Thanks for that helpful information. Could you provide me with some context regarding this section of your session recording, such as when it occurred?

M: This is about two or three minutes into the session. When I asked Amy what she wanted to work on today, she shared that she was feeling frustrated. I asked if she would tell me about her frustration, and she shared the following: Maddie starts the recording. Amy's voice sounds somewhat strained and angry.

A: I just don't understand where these people get off. I am already stressed out. I already don't know exactly how I am going to pay the babysitter at the end of the week, and then they assume I can stay late whenever any of these people are slow picking up their kids. I did it a few times when John was at home because I could, and I don't want to come off as not wanting to work or help out or whatever, but I can't do it all the time, and I have told them that. I have to be out the door at 5:25 to catch the 5:30 bus. My shift ends at 5:00! I'm not even getting paid for the half hour it takes me to get out of there. But they act like I can stay until 5:45, 6:00, 6:15. I am the only one the director ever asks to do it, or tells to do it. A lot of the other girls have their kids in the day care there, and they use that as an excuse to leave, like, "Oh, well we will go ahead and get out of your way." What?! You're not in my way. I need help! I need to get on the bus before I miss it and get back home to my neighborhood and pick up my kid, because I can't afford to have her in school where I'm working, unlike these other people. You have a car. You have a husband working or paying child support or whatever, and you only work part-time. This is not a job I'm doing just to get a good rate on this fancy day care. I don't have that money.

M: You sound really angry that your job requires you to stay late. 
A: But it's not required! Or at least they didn't tell me that when I was hired!

M: Maybe this would be a good place to pause the recording.

P: Okay. Do you remember how you were feeling at that point in the session? [affective inquiry]

M: I was anxious. She was so angry. She's talked about being angry before, but she's never actually been angry in session, like raising her voice and stuff.

P: So as her affect intensified, you noticed your anxiety increase. Do you have any ideas about that? Like what was going on for you in terms of thoughts or other feelings at that moment? [affective and cognitive inquiry]

M: Well, anxiety because I didn't know how to respond? Her anger kind of freaked me out. I guess I felt kind of scared of her. I've never had a client raise his or her voice like that.

P: Could we listen to that part again? [P rewinds the recording and they listen to the excerpt again.]

M: Now I am hearing so much more in that section. I don't even know where to start.

P: Well, how about we check in with your client? What do you imagine she was feeling then? [mutual perceptions inquiry]

M: Well, now that I am hearing it without my anxiety sort of crowding my brain, I hear that she is really angry, but I don't think it is about her "job requirements," or whatever it was that I said. I bet she felt really misunderstood by me in that moment. I feel bad now that I am realizing it.

P: What do you think she wanted from you? [expectations inquiry]

M: Validation. For someone to understand her situation. Maybe for me to get angry with her.

P: Was there anything you wanted to say to her at that moment but didn't say? [unstated agendas inquiry]

M: I guess it crossed my mind that she may have been feeling discriminated against at work due to her race or her social class, or maybe both.

P: What kept you from sharing that? [unstated agendas inquiry]

M: We've never really talked about race or class in our counseling sessions, and I guess I was a little nervous about maybe offending her or jumping to conclusions. But I do think that most of the people she works with are White and more well off financially, and that most of the kids at that day care are White-just based on where I know it is located. Now that I am listening to it again, it seems like her boss and her coworkers are taking advantage of her. She doesn't have a car. It doesn't seem like they are respecting her time or acknowledging the challenges that she has in terms of transportation, or her need to go pick up her kids.

P: Okay. Ready to listen to more?

M: Sure.

Maddie starts the recording again.

A: Nowhere in my contract does it specify that I am required to stay past 5:00. [A breathes in deeply and sighs. After a 10-second silence, she continues.] I feel like I'm going crazy. Is it me? Is it perfectly reasonable for my coworkers and the director to expect me to work overtime without extra pay? How is everybody so blind to this?!

M: Um.... Last time we met, you shared that you were looking forward to the three-day weekend. I was wondering if you wouldn't mind sharing how that went.

M: It might be helpful to stop the tape again. 
P: Sure. What do you think your client's perceptions of you were at that moment? [mutual perceptions]

M: I believe she thinks that I can't understand her, especially considering I neglected to acknowledge her experience. Instead, I changed the subject.

P: In that moment, when your client asked how everybody was so blind to the situation, did you feel anything in your body and, if so, how did it feel? [body sensations inquiry]

M: Yes, I felt butterflies in my stomach and I felt my shoulders become tense. I wasn't sure what to say or do. I felt her frustration and anger, and it made me feel very anxious.

P: Do you think your client was aware of what you were thinking and feeling at that moment? [mutual perceptions]

M: Yeah. After reviewing the recording, I think she did pick up on my discomfort and lack of understanding of her situation. I think that my discomfort might have been why she sighed. I wish I hadn't changed the subject so abruptly. That probably made it seem even more like I didn't understand her situation or that I was dismissive of it.

P: What were your intentions in giving that response? [unstated agendas inquiry]

M: She seemed so upset and perplexed. I guess I wanted her to feel better by changing the subject. I also suppose that it was somewhat self-serving. I didn't feel comfortable and I didn't know where to go in the session, so I asked her about her weekend.

P: Do you recall any images, memories, or pictures appearing in your mind at this moment? [images inquiry]

M: Interestingly, my friend's face popped into my head. One time, in high school, this friend was really upset and shared with me that other students had been picking on her because she is gay. Even though she thanked me for listening to her, she pointed out that there was no way I could really understand. In a way, the discomfort I felt in this session was similar. In both situations I got really nervous and changed the subject.

P: Okay. Is there anything else you recall from this section of the recording that you would like to process? [ending inquiry]

M: No, I don't think so. I feel like I have a lot to think about though, based on what we've already listened to and processed.

P: Okay, so what are your takeaways from this experience reviewing your session? [ending inquiry]

M: After listening to what the client was saying and how I responded to her, and now understanding how I believe she perceived me, my main takeaway is that I need to be more comfortable processing topics about race, SES [socioeconomic status], and discrimination. I noticed that my nervousness, coupled with the fact that I am White, likely contributed to her frustration. She probably thought that I couldn't understand her situation or that I was choosing not to.

P: What would you like to do based on the realizations that you have had in session today? [ending inquiry]

M: I would really like it if you could help me work on ways to respond appropriately to Amy, especially when she shares things about race, SES, and discrimination.

\section{Discussion}


This case example illustrates how supervisors can prepare supervisees for IPR as well as utilize IPR to facilitate multicultural awareness. With respect to preparation, before engaging in IPR, Paula and Maddie developed a strong supervisory working alliance, including discussion of their own cultural similarities and differences. This means they had established a relational bond, as well as motivation to perform supervisory tasks and accomplish supervisory goals (Bennett et al., 2012). The strong relational bond between Paula and Maddie and their cultural discussions likely facilitated Maddie's willingness to share with her supervisor a counseling session recording with a culturally diverse client with whom she struggled to connect. It also likely contributed to Maddie's willingness to participate in IPR and her sense of safety to process her self- and cultural awareness associated with race and class.

In addition, the case example demonstrates the importance of preparing supervisees for what to expect with IPR. This included Paula's describing to Maddie the purpose of the IPR intervention (e.g., slow things down a bit), discussing the supervisor and supervisee roles in IPR, and preparing her to recall her in-the-moment thoughts and feelings. The latter occurred when Paula asked Maddie to recall the thoughts and feelings she was having before the session began. Note that Maddie struggled at first to put herself in the mind-set to recollect her thoughts and feelings.

In reference to implementing IPR, Paula used a variety of IPR inquiries to help Maddie recall and process interchanges that she had with her client, Amy. Using a range of IPR prompts/inquiries, Paula asked Maddie to recall and share her thoughts, emotions, expectations, bodily responses, perceptions, and memories in relation to the counselor-client interpersonal exchanges. Paula also asked Maddie to discuss what she believed her client was thinking and feeling, as well as how her client was perceiving her. It is important to note that, as an IPR inquirer, Paula was very careful not to judge or analyze Maddie's counselor responses. Evaluation and judgment were avoided to cultivate a supportive space wherein Maddie could be open to recalling thoughts and feelings associated with her interchange with her client, including negative thoughts about her responses to the client and her discomfort with the client's affect. Paula also avoided instructing Maddie on topics such as self-awareness, cultural awareness, cultural responsiveness, and microinvalidation, as instruction may have reflected implicit undertones of evaluation that could have potentially affected recall in a negative way. The use of IPR does not mean such instruction or evaluation might not be needed or valuable, but separates the focus on raising self-awareness from such instruction. Through the use of IPR, Paula provided Maddie with a space to process how the client's behaviors impacted her and how she believed her own responses influenced the client. To wrap up the IPR intervention, Paula asked Maddie to share what she would like to do with the awareness she had gleaned, again honoring Maddie's willingness to be transparent about her thoughts and feelings. In terms of multicultural awareness, through IPR, Maddie was able to recognize some of her own subtle assumptions about "human behavior," as well as some "preconceived notions" and "personal limitations" (Sue et al., 1992, p. 481). She became aware of how she had unintentionally microinvalidated her client's reality by inaccurately reflecting content and by changing the subject. The IPR intervention also broached the topic of cultural responsiveness as well as Maddie's discomfort with processing race and class with her client. The IPR intervention concluded with Maddie expressing a desire to work with her supervisor to improve her ability to address cultural issues (i.e., race, class, discrimination) in session with clients. If Maddie had not been sufficiently insightful to come to the aforementioned realizations, Paula may have considered a few tactics. 
First, she could have continued the IPR intervention by listening to more of the recording to see if additional data could elicit multicultural awareness. Second, she could have modified her nondirective IPR role proportional to Maddie's perceived capacity to gain insights. In particular, she may have needed to step out of the inquirer role (and make this explicit to Maddie) to use immediacy to share her observations of Maddie's reluctance to delve into the cultural aspects of the counseling session.

\section{Implications for supervision practice}

Guideline 6 of the Best Practices in Clinical Supervision guidelines for counselors indicates, among other things, that supervisors "introduce issues of culture, diversity, power, and privilege within the supervisory and counseling relationships" (Borders et al., 2014, p. 38). Although clinical supervision is an appropriate and important setting to stress multicultural awareness (Bernard \& Goodyear, 2014), the process for doing so is not simple. In particular, topics associated with multicultural awareness, such as racism, implicit bias, prejudice, and contrastive cultural worldviews, can elicit strong emotional responses and defense mechanisms in students. The non-directive, non-evaluative, and non-judgmental focus of IPR may reduce the prevalence of defense mechanisms by providing supervisees with a secure space to explore and express their uncensored thoughts and feelings associated with multicultural encounters. This could lead to broader and deeper multicultural awareness for clinicians.

Conversely, while IPR may be effective for supervisees who have implicit cultural biases, it may not be appropriate for every supervisee. In particular, we recommend against using IPR with supervisees who possess explicit and unapologetic biases toward culturally diverse groups. In these cases, a more directive, remedial approach is likely necessary. It also is important that supervisors using IPR be aware of the potential to drift from their role as supervisor into the role of clinician. To avoid this slippery slope, supervisors should keep in mind the ultimate goal of supervision: to help supervisees develop their clinical competence. The use of IPR to elicit selfand cultural awareness, therefore, should be tied directly to facilitating client care and clinical growth, rather than the resolution of personal concerns.

\section{Implications for clinical supervision training}

Supervision trainers can both teach and employ IPR to help clinical supervisors improve the frequency and effectiveness with which they introduce and process multicultural topics in supervision. When supervisors emphasize culture in supervision, the supervisory working alliance, supervisee satisfaction ratings, and supervisory outcomes tend to improve (Ancis \& Marshall, 2010). IPR, with its non-directive and non-evaluative emphasis, may help supervisorsin-training feel more comfortable introducing topics related to culture in supervision, which, in turn, may increase the frequency with which they address cultural issues with supervisees. Clinical supervision trainers also may use IPR directly with their supervisors-in-training to develop multicultural supervision awareness. One possibility is that trainers could use IPR with the critical incidents model of supervision. For example, using recorded supervision sessions, trainers could request that supervisors-in-training identify "critical incidents" during their supervision sessions in which cultural topics were addressed or could have been discussed with supervisees. IPR then could be used to help supervisors-in-training recall their feelings and 
beliefs associated with that interchange, with the goal of increasing their multicultural awareness. The aim is to translate supervisors' awareness into increased breadth and depth of discussion with supervisees regarding culture.

\section{Future research}

Like other suggested supervision interventions to address multicultural issues in counseling, our conceptual thesis is not supported directly by empirical research, although indirect support can be garnered from the general research on the effectiveness of IPR in raising individuals' selfawareness. Nevertheless, research is needed to validate the thesis that IPR in supervision helps clinicians develop their multicultural awareness. A pre-/post-experimental design, comparing the difference between IPR and other supervision techniques on multicultural awareness development, would be particularly instructive. Qualitative analyses also would be beneficial, particularly in reference to understanding supervisees' experiences with IPR and the particular impressions related to culture that IPR produces. It also would be helpful to examine quantitatively relationships between IPR and the supervisory working alliance. Crockett and Hays (2015) found a positive relationship between supervisors' MCC and a supervisory working alliance, which, in turn, related to supervisees' satisfaction with supervision. It would be important to determine whether IPR positively influences the supervisory working alliance and if supervisors' MCC has a mediating effect on that relationship.

\section{Conclusion}

Although there are numerous calls to emphasize multicultural awareness in clinical supervision (e.g., Bernard \& Goodyear, 2014; Constantine, 1997; Sommer et al., 2009), few explicit interventions to do so have been described and illustrated. It is our thesis that IPR is a particularly salient intervention for indirectly challenging supervisees' unconscious and semiconscious cultural attitudes and beliefs, thus allowing them to work more effectively with their culturally diverse clients.

\section{References}

Ancis, J. R., \& Marshall, D. S. (2010). Using a multicultural framework to assess supervisees' perceptions of culturally competent supervision. Journal of Counseling \& Development, 88, 277-284. doi:10.1002/j.1556-6678.2010.tb00023.x

Baker, S. B., Daniels, T. G., \& Greeley, A. T. (1990). Systematic training of graduate-level counselors: Narrative and meta-analytic reviews of three major programs. The Counseling Psychologist, 18, 355-421.

Bennett, S., Mohr, J., Deal, K. H., \& Hwang, J. (2012). Supervisor attachment, supervisory working alliance, and affect in social work field instruction. Research on Social Work Practice, 23, 199-209. doi:10.1177/1049731512468492

Bernard, J. M., \& Goodyear, R. K. (2014). Fundamentals of clinical supervision (5th ed.). Boston, MA: Allyn \& Bacon. 
Borders, L. D. (1991). A systematic approach to peer group supervision. Journal of Counseling \& Development, 69, 248-252.

Borders, L. D., \& Brown, L. L. (2005). The new handbook of counseling supervision. Mahwah, NJ: Lawrence Erlbaum Associates.

Borders, L. D., Glosoff, H. L., Welfare, L. E., Hays, D. G., DeKruyf, L., Fernando, D. M., \& Page, B. (2014). Best practices in clinical supervision: Evolution of a counseling specialty. The Clinical Supervisor, 33, 26-44. doi:10.1080/07325223.2014.905225

Cary, D., \& Marques, P. (2007). From expert to collaborator: Developing cultural competency in clinical supervision. The Clinical Supervisor, 26(1/2), 141-157. doi:10.1300/J001v26n01_10

Cashwell, C. S., Looby, J., \& Housley, W. (1997). Appreciating cultural diversity through clinical supervision. The Clinical Supervisor, 15(1), 75-86.

Chao, R. C. (2012). Racial/ethnic identity, gender-role attitudes, and multicultural counseling competence: The role of multicultural counseling training. Journal of Counseling \& Development, 90, 35-44. doi:10.1111/j.1556-6676.2012.00005.x

Constantine, M. G. (1997). Facilitating multicultural competency in counseling supervision: Operationalizing a practical framework. In D. B. Pope-Davis \& H. L.

K. Coleman (Eds.), Multicultural counseling competencies: Assessment, education and training, and supervision (pp. 310-324). Thousand Oaks, CA: Sage.

Crews, J., Smith, M. R., Smaby, M. H., Cleborne, D., Torres-Rivera, E., Casey, J. A., \& Urbani, S. (2005). Self-monitoring and counseling skills-based versus interpersonal process recall training. Journal of Counseling \& Development, 83, 78-85.

Crockett, S., \& Hays, D. G. (2015). The influence of supervisor multicultural competence on the supervisory working alliance, supervisee counseling self-efficacy, and supervisee satisfaction with supervision: A mediation model. Counselor Education \& Supervision, 54, 258-273. doi: $10.1002 /$ ceas. 12025

Dickson, G. L., \& Jepsen, D. A. (2007). Multicultural training experiences as predictors of multicultural competencies: Students' perspectives. Counselor Education and Supervision, 47, 76-95.

Fong, M. L. (1994). Multicultural issues in supervision. Greensboro, NC: ERIC Clearinghouse on Counseling and Student Services. (ERIC Document Reproduction Service No. ED372346).

Garrett, M. T., Borders, L. D., Crutchfield, L. B., Torres-Rivera, E., Brotherton, D., \& Curtis, R. (2001). Multicultural supervision: A paradigm of cultural responsiveness for supervisors. Journal of Multicultural Counseling and Development, 29, 147-158. 
Harris, A., \& Werner, D. (1976). Often used inquirer leads. In N. I. Kagan (Ed.), Interpersonal process recall: A method of influencing human interaction (pp. 186-190). East Lansing, MI: Kagan, Michigan State University.

Inman, A. G., \& DeBoer Kreider, E. (2013). Multicultural competence: Psychotherapy practice and supervision. Psychotherapy, 50, 346-350. doi:10.1037/a0032029

Kagan, N. I. (1976). Interpersonal process recall: A method of influencing human interaction. East Lansing, MI: Kagan, Michigan State University.

Kagan, N. I. (1980). Influencing human interaction: Eighteen years with IPR. In A. K. Hess (Ed.), Psychotherapy supervision: Theory, research, and practice (pp. 262-283). New York, NY: Wiley.

Kagan, H., \& Kagan, N. (1997). Interpersonal process recall: Influencing human interaction. In C. E.Watkins Jr. (Ed.), Handbook of psychotherapy supervision (pp. 296-309). New York, NY: Wiley.

Kagan, N., \& Kagan, H. (1990). IPR: Validated model for the 1990s and beyond. The Counseling Psychologist, 18, 436-440.

Kagan, N. I., Krathwohl, D. R., Goldberg, D., Campbell, R. J., Schauble, P. G., Greenberg, B. S.,... Bondy, S. B. (1967). Studies in human interaction: Interpersonal process recall stimulated by videotape. (Research Rep. No. 20). East Lansing, MI: Educational Publishing Services.

Kagan, N., Krathwohl, D. R., \& Miller, R. (1963). Stimulating recall in therapy using video tape: A case study. Journal of Counseling Psychology, 10, 237-243. doi:10.1037/h0045497

Kingdon, M. A. (1975). A cost/benefit analysis of the interpersonal process recall technique. Journal of Counseling Psychology, 22, 353-357.

Ladany, N., Friedlander, M. L., \& Nelson, M. L. (2005). Critical events in psychotherapy supervision: An interpersonal approach. Washington, DC: American Psychological Association.

Lassiter, P. S., Napolitano, L., Culbreth, J. R., \& Ng, K. (2008). Developing multicultural competence using the structured peer group supervision model. Counselor Education and Supervision, 47, 164-178.

Leong, F. T. L., \& Wagner, N. S. (1994). Cross-cultural counseling supervision: What do we know? What do we need to know? Counselor Education and Supervision, 34, 117-131.

Ratts, M. J., Singh, A. A., Nassar-McMillan, S., Butler, S. K., \& McCullough, J. R. (2015). Multicultural and social justice counseling competencies. Retrieved from http://www.multiculturalcounseling.org/index.php?option=com content\&view=article\&id= 205: amcd-endorses-multicultural-and-social-justice-counselingcompetencies\&catid=1:1atest $\&$ Itemid $=123$ 
Sommer, C. A., Derrick, E. C., Bourgeois, M. B., Ingene, D. H., Yang, J. W., \& Justice, C. A. (2009). Multicultural connections: Using stories to transcend cultural boundaries in supervision. Journal of Multicultural Counseling and Development, 37, 206-218.

Sue, D. W., Arredondo, P., \& McDavis, R. (1992). Multicultural counseling competencies and standards: A call to the profession. Journal of Counseling \&Development, 70, 477-486.

Sue, D. W., Capodilupo, C. M., Torino, G. C., Bucceri, J. M, Holder, A. M. B., Nadal, K. L., \& Esquilin, M.(2007). Racial microaggressions in everyday life: Implications for clinical practice. American Psychologist, 62, 271-286.

Suthakaran, V. (2011). Using analogies to enhance self-awareness and cultural empathy: Implications for supervision. Journal of Multicultural Counseling \& Development, 39, 206-217.

Toporek, R. L., Ortega-Villalobos, L., \& Pope-Davis, D. B. (2004). Critical incidents in multicultural supervision: Exploring supervisees' and supervisors' experiences. Journal of Multicultural Counseling and Development, 32, 66-83.

\section{Author information}

Nathaniel N. Ivers is an assistant professor and the associate chair of the Department of Counseling at Wake Forest University and a Licensed Professional Counselor in North Carolina and Texas. The majority of his counseling practice has been with the Latina/o, Spanish-speaking, immigrant population in Winston-Salem, North Carolina. Nathaniel has worked as a bilingual counselor, bilingual alcohol counselor, private practitioner, and independent contractor providing counseling services to individuals, couples, and families. Nathaniel also has experience providing supervision in online and traditional formats, working with practicum students, counseling interns, and Licensed Professional Counseling Associates. Nathaniel's research interests and agenda are related to multicultural counseling competence, counseling with Latinos/as, and bilingualism.

Jennifer L. Rogers is an assistant professor in the Department of Counseling at Wake Forest University, where she teaches counseling skills and supervises clinical mental health interns. She is currently engaged in research exploring counselor trainees' affective and cognitive experiences in clinical supervision.

L. DiAnne Borders is Burlington Industries Excellence Professor in the Department of Counseling and Educational Development at The University of North Carolina at Greensboro, where she teaches clinical supervision and supervises doctoral students' clinical supervision internships. In her current research she is focused on novice supervisor development, supervision education and pedagogy, supervisor cognitions, and supervisory relationship dynamics. She was the recipient of the inaugural ACES Supervision Award in 2016.

Alison Turner offers counseling for individuals, couples, and families at the Mood Treatment Center, a private practice located in Winston-Salem, North Carolina and Greensboro, North 
Carolina. Her counseling focus is in working with trauma and posttraumatic stress disorder (PTSD), although she sees a variety of presenting concerns ranging from personality disorders to bipolar disorder, anxiety, and depression. Ali remains passionate about increasing research on multicultural counseling competencies, specifically the impact of multicultural counseling competencies on the therapist-client relationship and the supervisor-supervisee relationship. 